\title{
Custom Power Device in Multilevel Inverter for Power Quality Improvement
}

\author{
Geevarghese Mathew Kurian, P. Aruna Jeyanthy, D. Devaraj
}

\begin{abstract}
A dynamic voltage restorer (DVR) is a FACTS gadget, which is utilized fundamentally in transmission lines to remunerate the voltage list and voltage swell that happens on hold. A DVR is a circuit, which made out of intensity electronic parts like diodes and thyristors. It is generally utilized because of its miniature size and proficient activity. This paper proposes a cascaded inverter type DVR to repay voltage hang in the utilities for power appropriation, which is used for country zone advancement. The DVR infuses a voltage arrangement to the framework voltage. The multi carrier PWM strategy is utilized to produce terminating voltage to inverter. The proposed framework decreases the voltage list and complete consonant bending of the conveyance framework. The proposed framework is simulated utilizing the MATLAB/Simulink.
\end{abstract}

Index terms: Power quality, Multilevel inverter, Total harmonic distortion (THD), Dynamic voltage restorer (DVR), Multi carrier pulse width modulation (MCPWM).

\section{INTRODUCTION}

A good electric power quality within the allowable standard limits is of great importance in an electric power distribution network [1-5].Power quality is becoming an important concern nowadays due to many reasons. Quality of voltage taken from the utility or that supplied to the consumer is referred to as voltage quality. The fluctuation of voltage, current or frequency from its optimal value can lead to maloperation of the equipment and can be considered as a serious issue in the power quality. Overall, power quality can be represented as a mix of quality of the voltage and current.

Electric power is the corner stone for the economic progress for a developing nation like India. After the invention of electric power, many experiments are tried to enhance the distribution production, and usage of electricity. Since requirement of electric power is being increasing day by day, an efficient management of energy is required. Power quality is an important factor. Series threat faced by power system today is harmonic pollution. Frequency of supply, voltage, shape of waveform etc. determines the quality of electric power. These problems will oppose the transfer of the electricity.

Revised Manuscript Received on December 15, 2019.

Geevarghese Mathew Kurian, Assistant Professor, Kottayam Institute of Technology Kottayam, Kerala, India.

Prof. P. Aruna Jeyanthy, Faculty of Electrical and Electronics Engineering, Kalasalingam University. Madurai, Tamil Nadu, India.

Prof. D. Devaraj, Lecturer in Arulmigu Kalasalingam College of Engineering, Krishnankoil, Srivilliputtur, Virudhunagar, Tamil Nadu, India

In medium voltage and high power condition the introduction of multilevel inverter has become boon [12]. Although this method has some drawbacks [3].However, these multilevel inverters also have some disadvantages like the output voltage is comparatively less than the input voltage. In addition, operation in high frequency is not possible due to switching loss. Due to switching loss, harmonics cannot be controlled. There are different methods have been used for reducing harmonic contents in the system [6-8]. Also for the transmission of power, Output voltage needed to be amplified with the help of transformer. The power quality problem occurs due to the nonlinear load connected in the system. Voltage fluctuations and distortions happens when the power is transferred.

The power quality is being reduced as it transferred to a distance. I $n$ rural areas the power generating station and the load centre far apart from each other. The use of FLEXIBLE ac transmission systems (FACTS) in power system provides the advantage of enhancement of quality of power. The transfer capacity conjointly and the quality of power of ac system interconnections are improved [10]. Both Transmission and distribution (T\&D) networks forms the most critical part of power grid. As we progress towards micro-grid, it is most important to modernize the T\&D networks and convert it to "Micro-grid ready". For the past three decades the concept of flexible ac transmission systems (FACTS) has been well-popularised. With the enormous advancements in the technology of power electronics in the past few decades there has been a trend towards a new generation of FACTS devices. This novel FACTS technology has led to the transition of transmission networks from the old concept to the "smart" concept[11]. The proposed new DVR control system can support the load voltages -related power quality issues unrelated to the load current profile [12].According to $\mathrm{Wu}$, Jinn-Chang, seven level inverter structure will improve the efficiency of power quality management[13]. The Dynamic Voltage Restorer (DVR) is an effective method for the enhancement of power quality This System describes the working of a 15 level multilevel inverter with DVR for reduced harmonic distortion.

\section{PROPOSED SYSTEM}

In this system contains two parts. A charging part and an inverter part. Which is connected to the AC bus. An Hbridge topology is used for this inverter. The charging part consist of a solar panel, which used to charge the inverter battery. Here we use three solar panels, which is located at different places. The solar panel is the source energy to the inverter. 
The inverter will feed power to the load. The conventional multilevel inverters also have some frequency distortion problem. The total harmonic distortion of the inverter can be reduced by using this 15 level inverter. As per the IEEE 519 standard, the percentage of total harmonic distortion for high voltages must be less than $8 \%$. We proposed this system for rural area development. The load centres are at a distance from the power generating stations. Hence, we have to transmit the power to some distance. Then the problem of voltage sag and swell arises. For this, we are implementing a DVR in the transmission line at the load side.

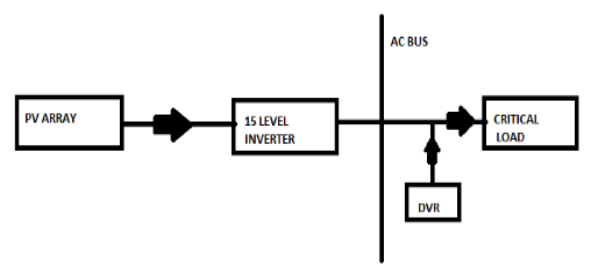

Fig. 1 Proposed system diagram

\section{III.INVERTER SYSTEM}

A 15 level inverter is used here. It consists of seven switches, three diodes and three power supply units. MOSFET is used as the switch. 15 level output is obtained from this inverter which has seven operating modes. As the number of stepped levels increases, the total harmonic distortion is also decreases. The functioning of the inverter can be divided into positive and negative half cycle. Each half cycle has seven working modes. Each mode of this system will produce one step the output of the entire system becomes more sinusoidal and hence improves the power quality.

Table I shows the switching combinations of different output levels.

\begin{tabular}{|c|c|c|c|c|c|c|c|}
\hline \multicolumn{7}{|c|}{ Switching combination } & \multirow[t]{2}{*}{ Output } \\
\hline Ss 1 & Ss2 & Ss3 & S1 & S2 & S3 & S4 & \\
\hline $\mathrm{ON}$ & $\begin{array}{l}\text { OF } \\
\mathrm{F}\end{array}$ & $\begin{array}{l}\text { OF } \\
\mathrm{F}\end{array}$ & $\begin{array}{l}\mathrm{O} \\
\mathrm{N}\end{array}$ & $\begin{array}{l}\mathrm{OF} \\
\mathrm{F}\end{array}$ & $\begin{array}{l}\mathrm{OF} \\
\mathrm{F}\end{array}$ & $\begin{array}{l}\mathrm{O} \\
\mathrm{N}\end{array}$ & $\mathrm{V}_{\text {OUT }}<\mathrm{V} 1$ \\
\hline $\begin{array}{l}\text { OF } \\
\mathrm{F}\end{array}$ & $\mathrm{ON}$ & $\begin{array}{l}\text { OF } \\
\mathrm{F}\end{array}$ & $\begin{array}{l}\mathrm{O} \\
\mathrm{N}\end{array}$ & $\begin{array}{l}\mathrm{OF} \\
\mathrm{F}\end{array}$ & $\begin{array}{l}\text { OF } \\
\mathrm{F}\end{array}$ & $\begin{array}{l}\mathrm{O} \\
\mathrm{N}\end{array}$ & $\mathrm{V} 1<\mathrm{V}_{\text {OUT }}<\mathrm{V} 2$ \\
\hline $\mathrm{ON}$ & $\mathrm{ON}$ & $\begin{array}{l}\text { OF } \\
\mathrm{F}\end{array}$ & $\begin{array}{l}\mathrm{O} \\
\mathrm{N}\end{array}$ & $\begin{array}{l}\mathrm{OF} \\
\mathrm{F}\end{array}$ & $\begin{array}{l}\mathrm{OF} \\
\mathrm{F}\end{array}$ & $\begin{array}{l}\mathrm{O} \\
\mathrm{N}\end{array}$ & $\begin{array}{l}\mathrm{V} 2<\mathrm{V}_{\text {OUT }}<\mathrm{V} 1+ \\
\mathrm{V} 2\end{array}$ \\
\hline $\begin{array}{l}\text { OF } \\
\mathrm{F}\end{array}$ & $\begin{array}{l}\text { OF } \\
\mathrm{F}\end{array}$ & $\mathrm{ON}$ & $\begin{array}{l}\mathrm{O} \\
\mathrm{N}\end{array}$ & $\begin{array}{l}\mathrm{OF} \\
\mathrm{F}\end{array}$ & $\begin{array}{l}\mathrm{OF} \\
\mathrm{F}\end{array}$ & $\begin{array}{l}\mathrm{O} \\
\mathrm{N}\end{array}$ & $\begin{array}{l}\mathrm{V} 1+\mathrm{V}_{2}<\mathrm{V}_{\text {OUT }}<\mathrm{V} \\
3\end{array}$ \\
\hline $\mathrm{ON}$ & $\begin{array}{l}\text { OF } \\
\mathrm{F}\end{array}$ & $\mathrm{ON}$ & $\begin{array}{l}\mathrm{O} \\
\mathrm{N}\end{array}$ & $\begin{array}{l}\text { OF } \\
F\end{array}$ & $\begin{array}{l}\mathrm{OF} \\
\mathrm{F}\end{array}$ & $\begin{array}{l}\mathrm{O} \\
\mathrm{N}\end{array}$ & $\mathrm{V}_{3}<\mathrm{V}_{\mathrm{OUT}}<\mathrm{V}_{3}+\mathrm{V}$ \\
\hline $\begin{array}{l}\text { OF } \\
\mathrm{F}\end{array}$ & $\mathrm{ON}$ & $\mathrm{ON}$ & $\begin{array}{l}\mathrm{O} \\
\mathrm{N}\end{array}$ & $\begin{array}{l}\mathrm{OF} \\
\mathrm{F}\end{array}$ & $\begin{array}{l}\mathrm{OF} \\
\mathrm{F}\end{array}$ & $\begin{array}{l}\mathrm{O} \\
\mathrm{N}\end{array}$ & $\begin{array}{l}\mathrm{V}_{3}+\mathrm{V}_{1}<\mathrm{V}_{\mathrm{OUT}}<\mathrm{V} \\
{ }_{2+} \mathrm{V}_{3}\end{array}$ \\
\hline $\mathrm{ON}$ & $\mathrm{ON}$ & $\mathrm{ON}$ & $\begin{array}{l}\mathrm{O} \\
\mathrm{N}\end{array}$ & $\begin{array}{l}\text { OF } \\
\mathrm{F}\end{array}$ & $\begin{array}{l}\mathrm{OF} \\
\mathrm{F}\end{array}$ & $\begin{array}{l}\mathrm{O} \\
\mathrm{N}\end{array}$ & $\begin{array}{l}\mathrm{V}_{3}+\mathrm{V}_{1}<\mathrm{V}_{\text {OUT }}< \\
\mathrm{V} 1+\mathrm{V} 2_{+} \mathrm{V}_{3}\end{array}$ \\
\hline
\end{tabular}




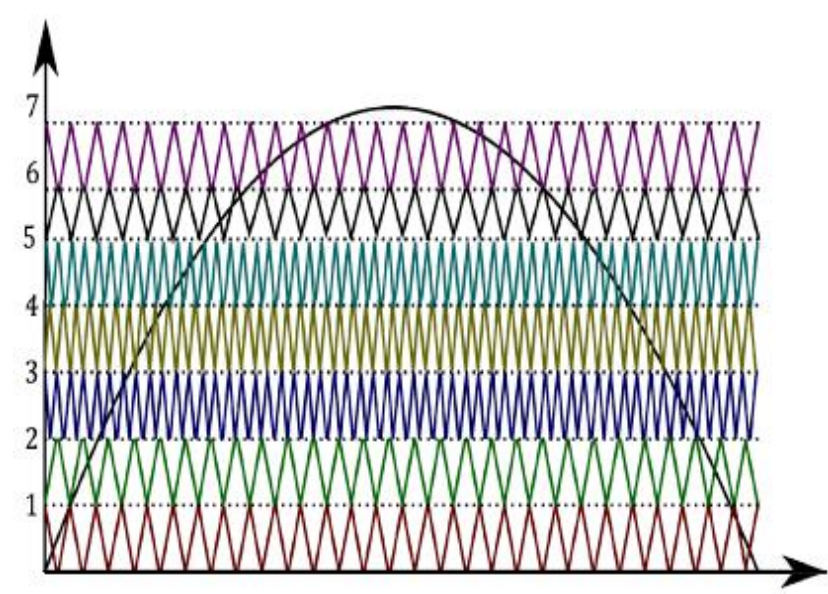

Fig. 4 . Multicarrier PWM

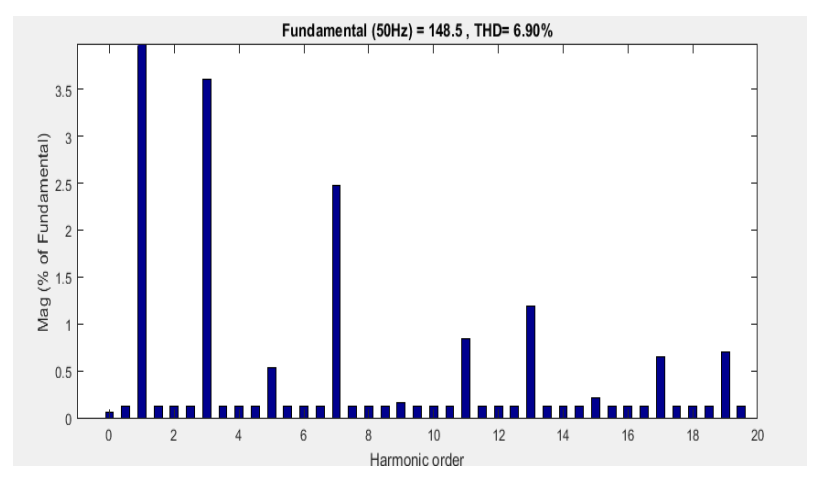

Figure 5. THD value measured from FFT analysis.

\section{VI.SIMULATION RESULTS}

To confirm the ability of the proposed scheme, the system is simulated using the MATLAB/Simulink. For the simulation purpose, we are using three different DC sources instead of solar panel inputs. The input voltage source of voltages is $20 \mathrm{~V}, 40 \mathrm{~V}$ and $60 \mathrm{~V}$. We can adjust the voltage levels. As the number of stepped levels increases then the harmonics will be decreases. In this system used low frequency switching mechanism, so the harmonics issues will be reduced. By implementing the proposed inverter, we can reduce the percentage of total harmonics to $6.9 \%$ which is shown in figure 5. However, it is noticed that the sag and swell are still there in the transmitted voltage. The voltage injected by the DVR compensates it. The THD given by the DVR is $5.04 \%$, which is nearly at the IEEE standard 519.

\section{CONCLUSION}

The paper describes the application of a 15 level multilevel inverter. It is used to eliminate the harmonics in the system. As the levels increases, the percentage of total harmonics decreases. The THD found at the multilevel inverter will be $6.9 \%$. As the power, quality is being reduced as the power is transferred to a distance, it will be improved by the use of DVR in the load side. The voltage sag and swell will be reduced. The THD measured in the load side will be $5.04 \%$. The proposed system satisfies the IEEE 519 standard.

\section{FUTURE SCOPE}

The system can be implemented for the development of rural areas. We can use solar panel as the source of energy to the inverter. This renewable energy can be implemented to face the energy scarcity. The hardware can be adapted to the rural areas, which is far away from the generating stations, and to the isolated areas. By using PI controller instead of the DVR, we can reduce the percentage of THD to an extreme reduced level.

\section{REFERENCES}

1. Geevarghese Mathew Kurian, Prof P. Aruna Jeyenthy, Prof. D. Devaraj, P.G. Anilkumar, Dept. of EEE, Kalasalingam University, "RTC based solar power multi- level Inverter", IEEE transactions on 2018.

2. Cheng-Han Hsieh, Tsorng-Juu Liang, Fellow, IEEE, ShihMing Chen, and Shih-Wen Tsai, Design and implementation of a novel

multilevel DC to AC inverter, IEEE Transactions on Industry Applications 2016.

3. Krishna Kumar Gupta; Alekh Ranjan; Pallavee Bhatnagar; Lalit Kumar Sahu, Shailendra Jain, "Multilevel inverter topologies with reduced device count: a review" IEEE Transactions on Power Electronics, 2016, Page: 135 - 151.

4. Alian Chen, Xiangning He, "Research on the hybrid clamped multilevel inverter topologies", IEEE Transactions on Industrial Electronics, 2006.

5. Sid-Ali Amamra, Kamal Meghriche, Abderrezzak Cherifi, Bruno Francois, Multilevel inverter for Renewable Energy Grid Integration, IEEE Transactions on Industrial Electronics, 2017.

6. Ehsan Najafi, Abdul Halim Mohamed Yatim, Design and Implementation of a New multilevel inverter topology", IEEE Transactions on Industrial Electronics, 2012.

7. Vincent Roberge, Mohammed Tarbouchi, and Francis Okou, "Strategies to Accelerate Harmonic Minimization in Multilevel Inverters Using a Parallel Genetic Algorithm on Graphical Processing Unit", IEEE transactions on power electronics, 2014.

8. Sze Sing Lee, Bing Chu, Nik Rumzi Nik Idris, Hui Hwang Goh, and Yeh En Heng, IEEE members, "Switched-Battery Boost-Multilevel Inverter with GA Optimized SHEPWM for Standalone Application", IEEE transactions on industrial electronics, 2015

9. Zainal Salam, Ahmed Majed, Abdul Moeed Amjad, University Technology Malaysia, "Design and implementation of 15-level cascaded multi-level voltage source inverter with harmonics elimination pulse-width modulation using differential evolution Method", IET research article, 2015.

10. Geevarghese Mathew Kurian, Jerlin Mathew, Prof P. Aruna Jeyenthy, Prof. D. Devaraj Dept. of EEE, Kalasalingam University, "Standalone Multilevel Inverter Using DVR for Power Quality Improvement", IEEE Conference INCOS 2019.

11. Fang Z. Peng, "Flexible AC transmission systems (FACTS) and resilient AC distribution systems (RACDS) in smart grid", proceedings of IEEE, 2017.

12. Manik Prdhan, Mahesh K. Mishra, "Dual P- Q theory based energy optimized Dynamic voltage restorer for power quality improvement in a distribution system", IEEE transactions on industrial electronics, 2019.

13. Wu, Jinn-Chang, and Chia-Wei Chou. "A Solar Power Generation System with a Seven-Level Inverter", IEEE Transactions on Power Electronics, 2014. 


\section{AUTHORS PROFILE}

Geevarghese Mathew Kurian Completed B-tech in Electrical and Electronics engineering in 2007 from Mahatma Gandhi University, and ME in Power systems from Anna University. Two years experience in Kerala state Electricity Board. I am working as assistant professor in Kottayam Institute of Technology and science 2012 .Currently pursing $\mathrm{PhD}$ In Power Quality at Kalasalingam University Tamil Nadu.

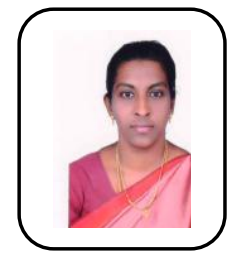

Prof. P. Aruna Jeyanthy Completed B.E in Electrical and Electronics Engineering from Madurai Kamaraj University and M.E in power systems from Annamalai University, also completed Ph.D in electrical engineering on Evolutionary Algorithmbased Techniques for Voltage Security Enhancement from Anna University. currently works as the Faculty of Electrical and Electronics Engineering Kalasalingam University. She has organized various Conferences, Seminars and conducted many workshops. She has chaired various technical sessions in many National and International Conferences. She has published papers in 29 international journals and 8 national journals. She has received many number of awards, Prizes and Honors for paper presentations and her valuable services in this field.

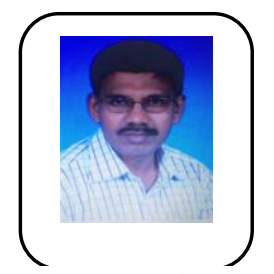

Prof. D. Devaraj Completed B.E and M.E in Electrical \& Electronics Engineering and Power System Engineering in the year 1992 and 1994, respectively, from Thiagarajar College of Engineering, Madurai. From 1994 to 1997, he worked as a Lecturer in Arulmigu Kalasalingam College of Engineering, Krishnankoil. He obtained his Ph.D degree from IIT Madras, Chennai in the year 2001. Since 2001, he is working as a faculty in the Electrical \& Electronics Engineering department of Kalasalingam University. He has organized 6 Conferences, 8 Seminars and conducted 10 workshops. He has published 105 papers in Journals and presented 250 papers in conferences. $\mathrm{He}$ has chaired 15 technical sessions in various National and International Conferences. He has Supervised 15 Ph.D, 2 M.S and 25 M.E thesis. Presently, he is guiding $8 \mathrm{Ph} . \mathrm{D}$ scholars. His research interest includes Power system security, Voltage stability, Smart grid, Evolutionary algorithms, Neural network and Data Mining. He is a senior member IEEE. Presently, he is the Dean - Academic, Senior Professor/EEE at Kalasalingam University, Krishnankoil. 